\title{
Free Radicals in X-Irradiated Ethylene Glycol Crystals
}

\author{
O. Awadelkarim, O. Claesson, and A. Lund \\ Department of Physics and Measurement Technology, Linköping University, Linköping, Sweden
}

Z. Naturforsch. 43a, 633-637 (1988); received April 27, 1988

ESR experiments aiming at clarifying the structure of radicals present in $\mathrm{X}$-irradiated crystals of ethylene glycol and other diols are reported. By comparison with data for the corresponding glasses it is concluded that a major source of free radicals is the decomposition of trapped electrons. The radical structure is identified.

\section{Introduction}

This investigation is concerned with the effect of ionising radiation on ethylene glycol and similar substances in crystalline form. Ethylene glycol can freeze either as a glass or a crystal. Several studies have been made on the glass, expecially with respect to trapped electrons [1-3], but crystals have not been examined before as far as we know. Ethylene glycol has been considered as a prototype for more complex compounds like carbohydrates. Radiation damage in carbohydrates has been investigated to a considerable extent, cf. [4] for a review.

Before the pioneering work of Box and coworkers the role of trapped electrons as a primary reduction product in X-irradiated crystalline carbohydrates and other polyhydroxy compounds at low temperature was unclear [5-7].

In the present study, the samples were irradiated at a relatively high temperature $(77 \mathrm{~K})$, and trapped electrons were not observed. Previous studies have indicated that the primary oxidation and reduction products decompose to free radicals cf. [8] and papers cited therein.

\section{Experimental}

Ethylene glycol was distilled under reduced pressure and dried over $\mathrm{MgSO}_{4} \cdot\left(\mathrm{CH}_{2} \mathrm{OD}\right)_{2}$ was prepared by mixing equal volumes of $\left(\mathrm{CH}_{2} \mathrm{OH}\right)_{2}$ and $\mathrm{D}_{2} \mathrm{O}$. The excess water was distilled off and a new portion of $\mathrm{D}_{2} \mathrm{O}$ was added. The procedure was repeated three times. The isotopic purity checked by IR was $92 \% \mathrm{D}$ or better. Several other diols used in this investigation were treated in a similar way. The dessiccated liquids were stored until used.

Structural studies by ESR were made on crystalline samples which were freed of dissolved air by pump- thaws on a vacuum line. The ESR sample tubes containing the liquid were slowly lowered into a cooling bath maintained at a temperature slightly lower than the melting point of the diol. The ESR spectra were anisotropic, indicating that single crystals had been formed.

Frozen glasses for ESR studies were formed by rapid freezing of degassed samples in liquid nitrogen. In some cases it was necessary to add a small amount of $\mathrm{H}_{2} \mathrm{O}$ or $\mathrm{D}_{2} \mathrm{O}$ to prevent crystallisation which occurred for instance upon cooling of the dried ethylene glycol samples.

ESR measurements were made on the samples after $\mathrm{X}$-irradiation at $77 \mathrm{~K}$. First derivative spectra were recorded with a Varian E9 spectrometer using $100 \mathrm{kHz}$ magnetic field modulation. The thermal decay of radicals was investigated by warming the samples in a thermostated stream of nitrogen gas. Single crystal measurements were made at $77 \mathrm{~K}$ and after heat treatments at selected temperatures.

\section{Results and Discussion}

ESR experiments aiming at clarifying the structure of radicals present in the crystals were performed on ethylene glycol, 1,4-butanediol, and briefly on 1,10-decanediol. Decay kinetics experiments of trapped electrons were performed on glasses of ethylene glycol, 1,3-propanol, 1,5-pentandiol, and briefly on 1,3- and 2,3-butanediol. The results will be described in detail in the case of ethylene glycol and more briefly for the other diols.

\section{Free Radical Structure in Ethylene Glycol from ESR Single Crystal Data}

Irradiations and ESR measurements on ethylene glycol single crystals in the dark were performed in an 
attempt to observe trapped electrons. The search was negative, i.e. the spectra remained unchanged after photobleaching with filtered light, contrary to the case of glassy matrices described in the literature and below. Annealing of the sample irradiated at $77 \mathrm{~K}$ by warming to $-30^{\circ} \mathrm{C}$ and recooling to $77 \mathrm{~K}$ gave better resolution without affecting the main features of the spectra. The resolution was also better in $\left(\mathrm{CH}_{2} \mathrm{OD}\right)_{2}$ than in $\left(\mathrm{CH}_{2} \mathrm{OH}\right)_{2}$. A crystal of $\left(\mathrm{CH}_{2} \mathrm{OD}\right)$, annealed at $-30^{\circ} \mathrm{C}$ was therefore selected for detailed analysis.

Data were first obtained by rotating the sample in steps of $10^{\circ}$ about the sample tube axis, hereafter called $z$. The sample tube was then cut and a piece of the crystal was aligned for rotation about a new axis called $x$. The spectrum obtained with the magnetic field parallel to $x$ is shown in Figure 1. The choice of the $x$ axis was arbitrary except that it was at right angles to $z$. Finally a rotation was made about the $y$ axis perpendicular to $x$ and $z$. The experimental data were analysed by standard methods to give the $g$ and hyperfine coupling tensors collected in Table 1, (see [9]).

As can be seen, the $g$-tensor anisotropy is slight and the two hyperfine couplings may be assigned to an $\alpha$ - and a $\beta$-proton, respectively. This immediately leads to the assignment $\dot{\mathrm{C}} \mathrm{HODCH} \mathrm{H}_{2} \mathrm{OD}$, a $\pi$-electron radical obtained by scission of a $\mathrm{C}-\mathrm{H}$ bond.

The ethylene glycol molecule is probably in a gauche conformational form because of intramolecular hydrogen bonding between the hydroxyl groups [10].

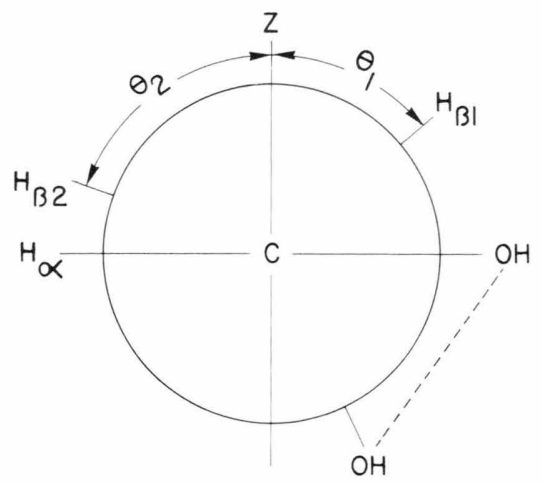

The following relation has been proposed for $\beta$-proton hyperfine couplings;

$$
a_{\beta}=\varrho\left(A_{0}+A_{2} \cos ^{2} \theta\right)
$$

with $\theta$ the dihedral angle, $\varrho$ the $\pi$-electron spin density on $C_{\alpha}$, and $A_{0} \approx 0, A_{2} \approx 50 \mathrm{G}$ [11].

The relation

$$
a_{\alpha}=Q \varrho
$$

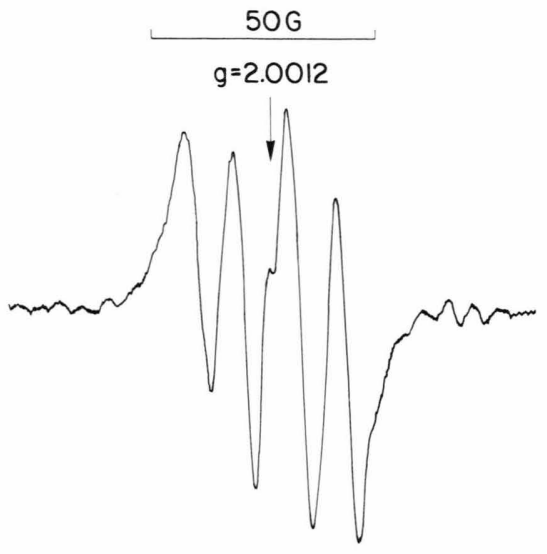

Fig. 1. ESR spectrum of the DOC $\mathrm{HCH}_{2} \mathrm{OD}$ radical in a single crystal of ethylene glycol, $\left(\mathrm{CH}_{2} \mathrm{OD}\right)_{2}$, after X-irradiation at $77 \mathrm{~K}$ and thermal annealing at $-30^{\circ} \mathrm{C}$. The magnetic field is along an axis $(\mathrm{x})$ which gives good resolution.

Table 1. $g$ - and hyperfine coupling tensors (in $\mathrm{G}$ ) for the DOC $\mathrm{CHCH}_{2} \mathrm{OD}$ radical in an irradiated ethylene glycol crystal. The $x y z$ axes are arbitrary.

\begin{tabular}{ccrrr}
\hline & $\begin{array}{c}\text { Principal } \\
\text { values }\end{array}$ & \multicolumn{3}{c}{ Direction cosines with respect to } \\
\cline { 3 - 5 } & & \multicolumn{1}{c}{$x$} & \multicolumn{1}{c}{$y$} & \multicolumn{1}{c}{$z$} \\
\hline$g$ & 2.0019 & 0.848 & 0.514 & -0.129 \\
& 2.0027 & 0.354 & -0.368 & 0.860 \\
\multirow{4}{*}{$A_{\alpha}$} & 2.0039 & -0.394 & 0.775 & 0.494 \\
& 25.9 & -0.685 & 0.624 & -0.377 \\
& 17.1 & 0.720 & 0.659 & -0.219 \\
$A_{\beta}$ & 4.4 & -0.112 & 0.421 & 0.900 \\
& 12.2 & -0.508 & 0.845 & 0.170 \\
& 10.9 & 0.081 & -0.150 & 0.986 \\
& 8.2 & 0.858 & 0.514 & 0.008 \\
\hline
\end{tabular}

with $Q \approx 25 \mathrm{G}$ is valid for $\pi$-electron radicals [11]. (1) and (2) gives $\theta_{1}=55^{\circ}, \varrho=0.63$. The computed coupling for $a(\beta 2) \approx 5 \mathrm{G}$ is small, a possible reason why it is not experimentally resolved. Very probably hydrogen bonding occurs in the radical as well (dashed line in the figure). A further stabilisation may occur by hyperconjugation which is effective for the geometry indicated (small value of $\theta(\mathrm{OH})$ ) [12].

The above mentioned considerations apply to a rigid structure in a crystal. In the liquid phase the parameters $g=2.00308, a_{\alpha}=17.54 \mathrm{G}$ and $a_{\beta 1}=a_{\beta 2}$ $=9.94 \mathrm{G}$ were obtained [13]. The main difference is that the two $\beta$-protons are equivalent, possibly because of motion about the $\mathrm{C}-\mathrm{C}$ bond.

The species $\mathrm{H}_{2} \dot{\mathrm{C}}-\mathrm{COH}$ was observed in the liquid state during photolysis of an acidic aqueous solution 
of ethylene glycol containing a small amount of $\mathrm{H}_{2} \mathrm{O}_{2}$ [14]. This species was not observed here, which is in agreement with the observation that acid is required for the reaction

$$
\mathrm{H}_{2} \mathrm{COH} \dot{\mathrm{C}} \mathrm{HOH} \rightarrow \mathrm{H}_{2} \dot{\mathrm{C}}-\mathrm{COH}+\mathrm{H}_{2} \mathrm{O} \text {. }
$$

It is in contrast, however, to indications that dehydration of hydroxyalkyl radicals might occur even in the crystalline state $[15,16]$.

\section{ESR Measurements on Ethylene Glycol Glass}

Solvated electrons become trapped at $77 \mathrm{~K}$ in many alcohol glasses including ethylene glycol, cf. [17] for a review. Much of the solvated electron structure in glassy matrices has been obtained by spectroscopic methods like ESR and, more recently, Electron Spin Echo Modulation, ESEM [18]. A model for the solvation structure of electrons in ethylene glycol has been obtained from an ESEM study [19]. A summary of experimental ESR data for trapped electrons in several diol glasses is given in Table 2.

The ESR spectrum due to trapped electrons in $\left(\mathrm{CH}_{2} \mathrm{OD}\right)_{2}$ disappeared upon illumination with filtered light $(\lambda>540 \mathrm{~nm})$ or warming $(T>150 \mathrm{~K})$. At the same time a three-line spectrum grew in intensity. The spectrum is in agreement with the single crystal data for $\mathrm{DOC} \mathrm{HCH}_{2} \mathrm{OD}$, indicating that the same radical is trapped in the glass and with a similar geometry. Thus, one pathway for the formation of these radicals is by the decomposition of the solvated electron. The reaction mechanism for the decomposition has been discussed and may occur in two steps [20]: $\mathrm{R} \mathrm{CH}_{2} \mathrm{O}-\mathrm{H} \ldots \mathrm{e}^{-} \ldots \mathrm{H}-\mathrm{OCH}_{2} \mathrm{R} \rightarrow \mathrm{RCH}_{2} \mathrm{O}^{-}+\mathrm{H}$ $+\mathrm{HOCH}_{2} \mathrm{R} \rightarrow \mathrm{H}_{2}+\mathrm{HOC} \dot{\mathrm{C}} \mathrm{R}$.

Table 2. ESR parameters of trapped electrons in glasses and crystals of diols. The data were obtained at $4.2 \mathrm{~K}$ for $\mathrm{HO}\left(\mathrm{CH}_{2}\right)_{6} \mathrm{OH}$ and $\mathrm{HO}\left(\mathrm{CH}_{2}\right)_{8} \mathrm{OH}$, and at $77 \mathrm{~K}$ in the other cases.

\begin{tabular}{llll}
\hline Matrix & $g$ & $\begin{array}{l}\text { Line width } \\
(\mathrm{G})\end{array}$ & Remarks \\
\hline $\mathrm{HO}\left(\mathrm{CH}_{2}\right)_{2} \mathrm{OH}_{2}$ & 2.0018 & 12.5 & glass \\
$\mathrm{DO}\left(\mathrm{CH}_{2}\right)_{2} \mathrm{OD}$ & 2.0018 & 5.0 & glass \\
$\mathrm{HO}\left(\mathrm{CD}_{2}\right)_{2} \mathrm{OH}$ & 2.0018 & 7.0 & glass \\
$\mathrm{DO}\left(\mathrm{CH}_{2}\right)_{3} \mathrm{OD}$ & 2.0019 & 4.5 & glass \\
$\mathrm{DO}\left(\mathrm{CH}_{2}\right)_{4} \mathrm{OD}$ & 2.0014 & 6.0 & glass \\
$\mathrm{DO}\left(\mathrm{CH}_{2}\right)_{5} \mathrm{OD}$ & 2.0014 & 5.0 & $\begin{array}{l}\text { glass } \\
\text { crystal, } \\
\text { resolved hf, [22] } \\
\mathrm{HO}\left(\mathrm{CH}_{2}\right)_{6} \mathrm{OH}\end{array} 2.0012$ \\
$\mathrm{HO}\left(\mathrm{CH}_{2}\right)_{8} \mathrm{OH}$ & 2.0012 & & $\begin{array}{l}\text { crystal, } \\
\text { resolved hf, [22] } \\
\text { crystal }\end{array}$ \\
$\mathrm{DO}\left(\mathrm{CH}_{2}\right)_{10} \mathrm{OD}$ & 2.0012 & 5.5 & \\
\hline
\end{tabular}

\section{Comparison with Pulse Radiolysis Measurements}

The transient optical spectra from pulse radiolysed ethylene glycol have been reported to have maximum absorption at $550-650 \mathrm{~nm}$ in the pure and aqueous glasses at $4-100 \mathrm{~K}[2,3]$. In the aqueous glass a strong IR band was observed in addition to the visible absorption. The IR band was assigned to electrons trapped by water molecules. The visible absorption in the pure compound has also been observed in the liquid state. We have confirmed that the absorption maxima are at $600 \mathrm{~nm}$ with spectral widths from 210 to $360 \mathrm{~nm}$ in ethylene glycol, 1,3-propanediol, 1,4-butanediol and 1,5-pentanediol. The ESR signals with $g<2.0023$, the free electron value, and the visible absorption were therefore assigned to the same trapped electron species. An attempt was made to support this assignment by measuring the kinetics by ESR and by pulse radiolysis in separate experiments on the same compounds (cf. [8] for applications of this technique to crystals). The Arrhenius parameters for the decay of trapped electrons from the ESR measurements in the frozen glass and from the pulse radiolysis of the corresponding liquids did not agree, however. The Arrhenius parameters from the pulse radiolysis experiments differed also between different batches, indicating that impurities affected the kinetics.

\section{ESR of Crystals and Glasses of $\mathrm{C}_{4}-\mathrm{C}_{10}$ diols}

ESR signals attributed to trapped electrons were observed in frozen glasses but not in crystals of 1,4-butanediol- $\mathrm{d}_{2}$ at $77 \mathrm{~K}$. Single crystal measurements showed that in the latter case DO $\dot{\mathrm{C}} \mathrm{H}\left(\mathrm{CH}_{2}\right)_{3} \mathrm{OD}$ was predominant. The nearly isotropic coupling constant of two equivalent $\beta$-protons was $a_{\beta}=25 \mathrm{G}$. The two spectra shown in Fig. 2 have $a_{\alpha}=32$ and $12 \mathrm{G}$, respectively, which are roughly the maximum and minimum values for an $\alpha-\mathrm{H}$ hyperfine coupling. The interpretation seemed rather straightforward and a complete determination of the coupling tensors was not made. The 1,4-butanediol molecules (and the radicals) probably have an extended geometry in the crystal, with a planar carbon chain and the hydrogens equally disposed above and below the plane through the carbon atoms, as is the case for 1,6-hexanediol [21]. Thus, there are no intramolecular hydrogen bonds as in ethylene glycol, which leads to a radical geometry with unequivalent $\beta-\mathrm{H}$. In the 1,4-butanediol glass, however, a five line spectrum with an average line separation of $19 \mathrm{G}$ was observed for the radical. If the 

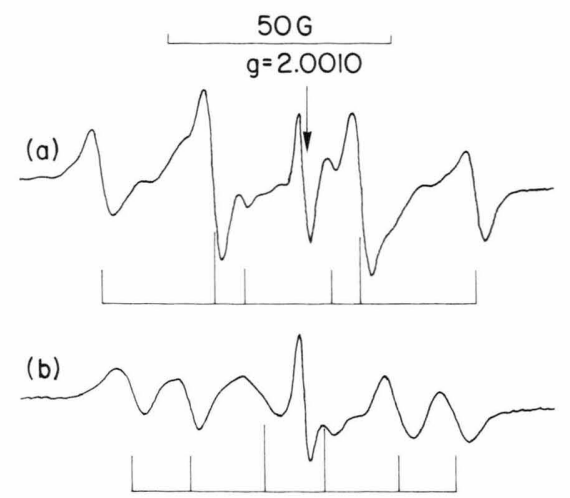

Fig. 2. ESR spectra of the DOCं $\mathrm{H}\left(\mathrm{CH}_{2}\right)_{3}$ OD radical in a single crystal of 1,4butanediol, $\mathrm{DO}\left(\mathrm{CH}_{2}\right)_{4} \mathrm{OD}$, after X-irradiation at $77 \mathrm{~K}$; a) at an orientation with a large $\alpha$-proton splitting, $a_{\alpha}=32 \mathrm{G}, a_{\beta}=25 \mathrm{G}$ $(2 \mathrm{H})$, b) at an orientation with a small $\alpha$-proton splitting, $a_{\alpha}=12 \mathrm{G}, a_{\beta}=25 \mathrm{G}$.

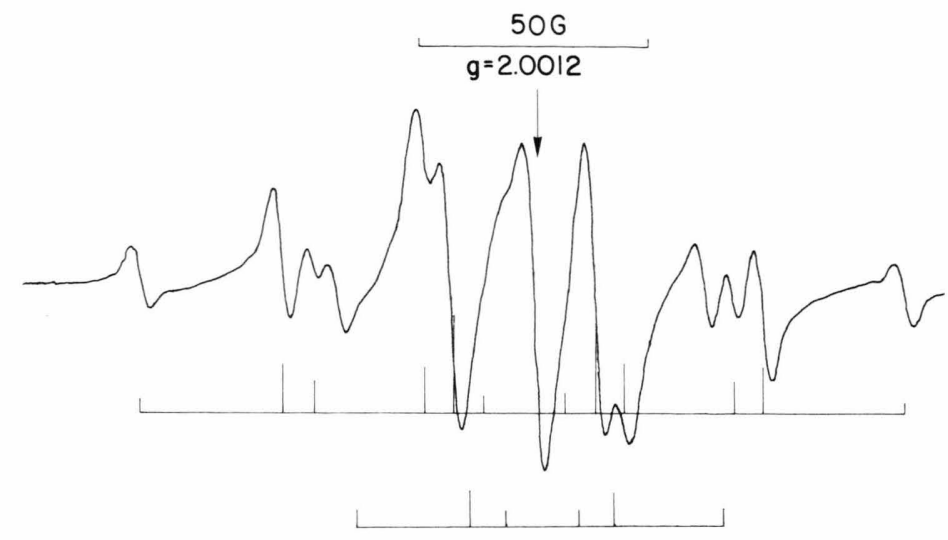

Fig. 3. ESR spectrum of the DO $\dot{C} H\left(\mathrm{CH}_{2}\right)_{9} \mathrm{OD}$ and $-\mathrm{CH}_{2} \dot{\mathrm{C}} \mathrm{HCH}_{2}-$ radicals marked by stickplots and the trapped electron marked by the arrow at $g=2.0012$ in a single crystal of 1,10-decanediol, $\mathrm{DO}\left(\mathrm{CH}_{2}\right)_{10} \mathrm{OD}$, after $\mathrm{X}$-irradiation at $77 \mathrm{~K}$. radical structure is the same as in the crystal, the geometry must be different. The geometry in the glass has not been deduced in this case or in the cases of 1,3-butanediol, 2,3-butanediol, 1,5-pentanediol and 2-methyl-pentanediol, which were briefly investigated.

In 1,6-hexandiol and 1,8-octanediol electrons become trapped after X-irradiation at $4 \mathrm{~K}$ [22]. The materials are crystalline. Trapped electrons were observed in deuterated 1,10-decanediol, $\mathrm{DO}\left(\mathrm{CH}_{2}\right)_{10} \mathrm{OD}$, crystals after irradiation at $77 \mathrm{~K}$. The signal disappeared after warmup to $120 \mathrm{~K}$ or illumination with $\lambda>630 \mathrm{~nm}$. The radicals present before and after these treatments were of two kinds, alkyl, $-\mathrm{CH}_{2}-\dot{\mathrm{C}} \mathrm{H}-\mathrm{CH}_{2}-$, and hydroxy-alkyl, $-\mathrm{CH}_{2}$ $-\dot{\mathrm{C} H O D}$, as indicated by the stick diagrams in Figure 3. The central line not accounted for by the stick diagrams was assigned to a trapped electron. After it had decayed by optical or thermal treatment the intensity of the $-\mathrm{CH}_{2}-\mathrm{C} \dot{C} O D$ increased as expected from the proposed reaction scheme [20]. The coupling constants for the radicals given in the figure legend were sufficient to identify the radicals; full tensor data were therefore not collected.

\section{Conclusions}

Electrons trapped in diol matrices are thermally more stable in the glassy than the crystalline state.
Stably trapped electrons at $77 \mathrm{~K}$ were only observed in crystals of 1,10-decanediol- $\mathrm{d}_{2}, \mathrm{DO}\left(\mathrm{CH}_{2}\right)_{10} \mathrm{OD}$. They were trapped, probably, in all diol glasses at 77 and could be definitely observed by ESR if $\mathrm{OH}$ was replaced by OD. As the electrons decayed thermally or by illumination, radicals of the hydroxy alkyl type grew in intensity. These radicals have been investigated to different degrees in several diols.

The geometry of the hydroxy alkyl radicals is similar in crystalline and glassy ethylene glycol. One major source of the radicals is from the decomposition of trapped electrons, i.e. the radicals are secondary reduction products. Since no other radicals were identified it must be assumed that another main source is from oxidation products. No dehydration occurs in the solid to form the $\dot{\mathrm{C}} \mathrm{H}_{2} \mathrm{COH}$ radical in contrast to the case of acidic solutions. In 1,4-butanediol the radicals are also of the hydroxyalkyl type, but in 1,10-decanediol both hydroxyalkyl and alkyl are present after irradiation, as reported previously in 1,8-octanediol [20].

\section{Acknowledgement}

This work was performed while the authors were at the Science Research Laboratory at Studsvik and was supported by the Natural Science Research Council and by SAREC. 
[1] H. Hase and T. Higashimura, Radiat. Phys. Chem. 12, 161 (1978).

[2] J. W. van Leeuwen, M. G. J. Heijmen, and H. Nauta, Radiat. Phys. Chem. 17, 367 (1981).

[3] J. Cygler, H. A. Gillis, N. V. Klassen, and G. G. Teather, Radiat. Phys. Chem. 17, 379 (1981).

[4] C. von Sonntag, Adv. Carbohydrate Chem. Biochem. 37, 7 (1980).

[5] H. C. Box, E. E. Budzinski, and H. G. Freund, J. Chem. Phys. 69, 1309 (1987).

[6] E. E. Budzinski, W. R. Potter, G. Potienko, and H. C. Box, J. Chem. Phys. 70, 5040 (1979).

[7] S. E. Locker and H. C. Box, J. Chem. Phys. 72, 828 (1980).

[8] A. Lund, G. Nilsson, and P.-O. Samskog, Radiat Phys. Chem. 27, 111 (1986).

[9] O. Claesson, A. Lund, J. P. Jörgensen, and E. Sagstuen, J. Magn. Reson. 41, 229 (1980).

[10] K. Krishnan and R. S. Krishnan, Proc. Ind. Acad. Sci. A 64, 111 (1966)

[11] J. E. Wertz and J. R. Bolton, Electron Spin Resonance, Elementary Theory and Practical Applications, McGraw Hill, New York 1972.
[12] P.-O. Samskog, L. D. Kispert, and D. P. Murray, Chem. Phys. Lett. 101, 106 (1983).

[13] R. Livingston and H. Zeldes, J. Chem. Phys. 44, 1245 (1966).

[14] R. Livingston and H. Zeldes J. Amer. Chem. Soc. 88, 4333 (1966).

[15] A. Gräslund and G. Löfroth, Acta Chem. Scand. Ser. B 29, 475 (1975).

[16] E. Sagstuen, A. Lund, O. Awadelkarim, M. Lindgren, and J. Westerling, J. Phys. Chem. 90, 5584 (1986).

[17] L. Kevan, Adv. Radiat Chem 4, 181 (1974).

[18] L. Kevan, Accounts Chem. Research 14, 138 (1981).

[19] M. Narayana, L. Kevan, P.-O. Samskog, A. Lund, and L. D. Kispert, J. Chem. Phys. 81, 2297 (1984)

[20] P.-O. Samskog, A. Lund, and G. Nilsson Chem. Phys. Lett. 79, 447 (1981).

[21] M. Lindgren, T. Gustafsson, J. Westerling, and A. Lund, Chem. Physics 106, 441 (1986).

[22] M. Ogasawara, M. Lindgren, A. Lund, and G. Nilsson, Chem. Phys. Lett 117, 254 (1985). 